\title{
Erratum to: Laser Beam Machining, Laser Beam Hybrid Machining, and Micro-channels Applications and Fabrication Techniques
}

\author{
Saied Darwish, Naveed Ahmed and Abdulrahman M. Alahmari
}

\section{Erratum to:}

\section{Chapter 17 in: A. Öchsner and H. Altenbach (eds.), Machining, Joining and Modifications of Advanced Materials, Advanced Structured Materials 61, DOI 10.1007/978-981-10-1082-8_17}

In Chapter 17, the authors missed to acknowledge that the corresponding project was financially supported by King Saud University, Vice Deanship of Research Chairs. The erratum chapter and the book has been updated with the change.

The updated original online version for this chapter can be found at 10.1007/978-981-10-1082-8_17

\section{S. Darwish $(\bowtie) \cdot$ N. Ahmed · A.M. Alahmari}

Princess Fatima Alnijiris's Research Chair for Advanced Manufacturing Technology

(FARCAMT), King Saud University, Riyadh, Saudi Arabia

e-mail: darwish@ksu.edu.sa

N. Ahmed

e-mail: anaveed@ksu.edu.sa

\author{
A.M. Alahmari \\ e-mail: alahmari@ksu.edu.sa
}

S. Darwish · N. Ahmed · A.M. Alahmari

Industrial Engineering Department, King Saud University, Riyadh, Saudi Arabia

S. Darwish · N. Ahmed · A.M. Alahmari

Advanced Manufacturing Institute, King Saud University, Riyadh, Saudi Arabia

N. Ahmed

Department of Industrial and Manufacturing Engineering, University of Engineering and Technology, Lahore, Pakistan 